J O U R N A O F French and Francophone Philosophy
REV UE DE LA

philosophie française et de langue française

\title{
Passeport Pour Une Immortalité Espérée
}

\section{Albert Memmi}

Journal of French and Francophone Philosophy - Revue de la philosophie française et de langue française, Vol XIX, No 2 (2011) pp 11-12

\author{
Vol XIX, No 2 (2011) \\ ISSN 1936-6280 (print) \\ ISSN 2155-1162 (online) \\ DOI $10.5195 /$ jffp. 2011.507 \\ www.jffp.org
}

\section{(c) EY-NC-ND}

This work is licensed under a Creative Commons Attribution-Noncommercial-No Derivative Works 3.0 United States License.

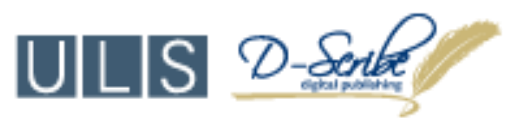

This journal is operated by the University Library System of the University of Pittsburgh as part of its D-Scribe Digital Publishing Program, and is co-sponsored by the University of Pittsburgh Press 


\section{Passeport Pour Une Immortalité Espérée}

\section{Albert Memmi}

Monsieur et madame Bernheim, Mesdames et Messieurs, chers lecteursamis, ou amis-lecteurs (car je souhaite que mes lecteurs deviennent mes amis, et mes amis des lecteurs),

Que pourrais-je ajouter après les paroles si intelligentes et si généreuses du professeur Annie Roselmann, dont je suis fier d'avoir été le professeur, comme elle vous l'a révélé elle-même, et à qui je suis reconnaissant, car avoir eu de tels élèves me rassure sur mon itinéraire.

À Tunis, à l'impasse Tronja, où je suis né, et où j'ai passé ma prime enfance, il existait des rites qui rythmaient notre vie commune (que nous partagions souvent avec nos concitoyens musulmans).

En voici un qui occupe encore ma mémoire.

À l'occasion des fêtes, ceux qui en avaient les moyens confectionnaient une quantité de gâteaux et en envoyaient de pleines assiettes à leurs proches.

Mais cette offrande appelait un retour: notre mère ne laissait jamais repartir une assiette vide: elle y mettait au moins quelques dragées, rescapées d'une bar mitzvah ou d'un mariage.

En m'offrant votre prix, vous me faites un délicieux cadeau. Voici donc, en retour, mes dragées: je vais vous confier un secret.

Je suis à l'âge des bilans, où jetant un regard d'ensemble sur la vie, on se demande si on l'a bien conduite; quelles en furent les erreurs et les réussites, les éventuels regrets.

Pour l'écrivain que je suis devenu, qu'aurai-je apporté à la corbeille de la culture commune? Pourquoi se préoccuper de la postérité, alors que je suis de ceux qui ne croient pas qu'il existe un autre monde? Pourquoi tant d'efforts obstinés pour édifier une espèce de passeport pour une immortalité espérée? 
Et bien, je n'ai découvert la réponse tâtonnante qu'il y a peu, et je vous la livre: il faut vivre, agir et penser maintenant, dans cette vie, comme si l'on était digne d'une immortalité espérée. Pour parler brièvement: rechercher et communiquer si possible la vérité. Se méfier donc des préjugés et des utopies, de toutes les dogmatiques, y compris ceux des siens. Sans soumission ni compromission. Telle est pour moi l'éthique du penseur et les fondements de ce que j'entends par philosophie.

Puis tâcher de mettre au point une forme adéquate pour sa communication: ce qui est le rôle de l'écrivain, que je me suis également efforcé d'être.

Certes il y a d'autres passeports: à chacun de souscrire pour le sien. Pour les penseurs et les artistes, l'œuvre est le passeport de cette espérance.

En me donnant votre prix, vous $\mathrm{m}^{\prime} \mathrm{y}$ confortez; soyez-en donc grandement remerciés.

(Allocution prononcée à la remise du prix Bernheim, à la Fondation du judaïsme français, le 16 mai 2011) 